\title{
Evaluation of Aeromagnetic Data of Ilesha Area of Oyo State Nigeria using Analytical Signal (ASM) and Local wavenumber (LWN)
}

\section{$*^{1}$ VITALIS, C. OZEBO; ${ }^{2}$ CHARLES, O. OGUNKOYA; ${ }^{2}$ GIDEON, O. LAYADE; ${ }^{2}$ VICTOR, MAKINDE; ${ }^{2}$ ADEYINKA, L. BISILIMI}

\author{
${ }^{1}$ Department of Physics, University of Lagos, Akoka, Yaba, Nigeria \\ ${ }^{2}$ Department of Physics, Federal University of Agriculture, Abeokuta, Nigeria \\ *Correspondence author Email: cozebo@unilag.edu.ng
}

\begin{abstract}
This paper presents the analysis and interpretation of an aeromagnetic data of Ilesha area, (Sheet 243) sourced from Nigeria Geological Survey Agency. The area is located between $7.5^{\circ} \mathrm{N}$ and $8.0^{\circ} \mathrm{N}$ of latitude and longitude $4.5^{\circ} \mathrm{E}$ to $5.0^{\circ} \mathrm{E}$. Two methods: Analytic Signal Method (ASM) and Local wavenumber (LWN) were used. These methods were used to process and analyse the data so as to generate the depth to magnetic sources as well as the source locations. The results obtained showed a shallower depth range limit for ASM between $0.348 \mathrm{~km}$ and $1.28 \mathrm{~km}$, which is less than the result of LWN within the range of $0.478 \mathrm{~km}-1.51 \mathrm{~km}$. The results also revealed more source locations in ASM result in comparison with LWN. The overall results of the methods have revealed the prospect of the lithology of the area for magnetic mineral exploration in the field of applied geophysics. (C) JASEM

https://dx.doi.org/10.4314/jasem.v21i6.28
\end{abstract}

Keywords: Aeromagnetic survey, Analytic signal, Magnetic Anomaly, Local wave number, lithology

Aeromagnetic geophysical method plays a distinguished role when compared with other geophysical methods in its rapid rate of coverage and low cost per unit area explored. The main purpose of aeromagnetic survey is to detect minerals or rocks that have unusual magnetic properties which reveal them by causing anomalies in the intensity of the earth's magnetic field (Jeffrey, 1997). Aeromagnetic survey map spatial variation in the magnetic field of the earth which occurs due to changes in the percentage of magnetite in the rock. It is used to produce geological interpretation of an area (Igboama and Ugwu 2004). Aeromagnetic data allow fast coverage of an accessible area for subsurface reconnaissance, which makes magnetic data analysis an essential tool of geophysical exploration. The processing of these data from the study area can provide important evidence of regional scale basement faulting in Ilesha, South-western Nigeria.

The airborne survey of the study area was carried out by Nigeria Geological Survey Agency (NGSA). The data was acquired along parallel flight line oriented in a NW - SE direction at 500m flight line spacing, while the tie lines are spaced at $2 \mathrm{~km}$ directed to NE $\mathrm{SE}$ direction. The aeromagnetic map used in this study extended between $7.5^{\circ} \mathrm{Nand} 8.0^{\circ} \mathrm{N}$ of latitude and from longitude $4.5^{\circ} \mathrm{E}$ to $5.0^{\circ} \mathrm{E}$ in Osun State Nigeria. The objective of this research work is to determine the depth to magnetic basement and its contact location in the study area. The international Geomagnetic Reference Field value used for correction is $32893.7334 n$ T. The inclination and declination angles of the ambient field were taken as $-9.45^{\circ}$ and $-2.95^{\circ}$ respectively. Andrew et al., (1994), discussed methods to produce the discrete analytic signal from a discrete real-valued signal. The result shows that the direct methods of zeroing the negative frequencies or using Hilbert transform filters have undesirable defects. He then presented an alternative which is similar to the 'quadrature' filters used in modern designs. Ansari and Alamdar (2009), used analytic signal as reduction to pole operator; applied it on synthetic magnetic data and on the real magnetic data from an area in Shahrood region of Iran. The result show that least difference is relevant to the causative body location and that analytic signal can be used as substituent method for conventional reduction to pole. Kayode et al., (2010), performed ground magnetic survey on the eastern part of Ilesha town. He focused on fault delineation in the study area. The results gave values for the total component measurements of ground magnetic anomaly as varied between -330gammas and 80gammas.

Ozebo and Nwodo, (2017) carried out a study to interpret aeromagnetic data over Nsukka and Udi areas of Enugu state. The result indicated that a sufficient hydrocarbon accumulation in the Nsukka axis of the study area is possible, as it has the minimum required thickness of sediments for commencement of oil formation from marine organic remains.

Geology of the Study Area: The geology of Ilesha area consists of Precambrian rocks that are typical of the basement complex of Nigeria (Rahaman, 1976). The major rock associated with Ilesha area form part of the Proterozoic schist belt of Nigeria which is predominantly developed in the western half of the 
country. In terms of structural features, and mineralization, the schist belts of Nigeria show considerable similarities to the Achaean Green Stone Belts (Kehinde-Philips and Gerd, 1995; Ajayi 1981; Rahaman 1976). Lithologically, the schist belt consists of metamorphosed pelitic to semi-pelitic rocks, quartzites, calc-silicates rocks, metaconglomerates and pebbly schists; amphibolites and metavolcanic rocks. Figures 1 and 2 shows the geological map and topographical map of the Study Area. Rocks in Ilesha schist belt are structurally divided into two main segments; the major fracture zone, usually called Iwaraja faults in the eastern part, and the Ifewara faults in the Western part. (Kayode et al 2010, Kayode 2009; Folami 1992; Elueze, 1986; Ozebo et al 2015).

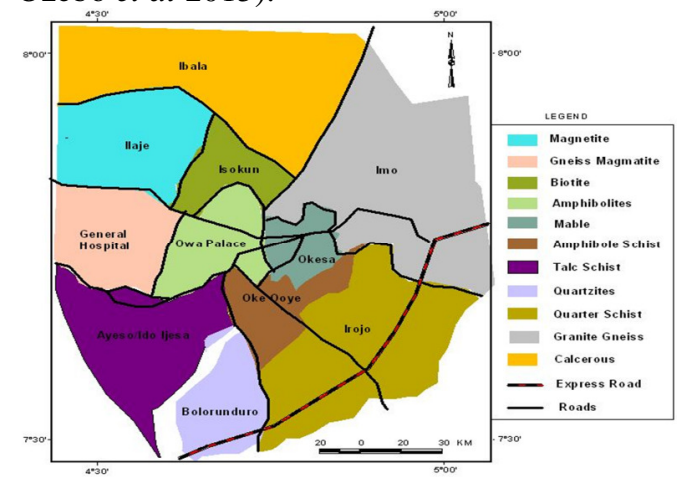

Fig 1: Geological map of the Study Area.

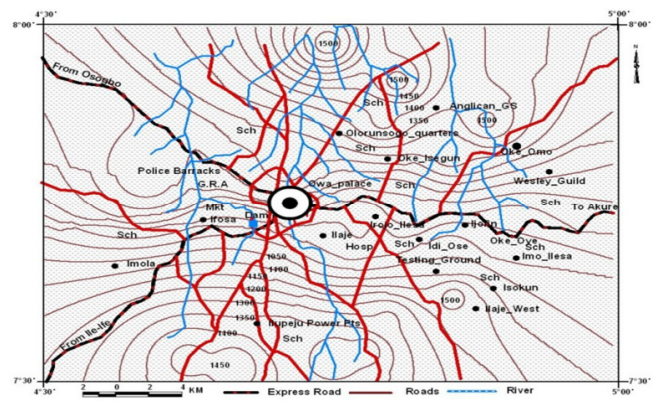

Fig 2: Topographical map of the Study Area.

\section{MATERIALS AND METHODS}

The aeromagnetic data of Ilesha area (sheet 243) was obtained as part of a nationwide aeromagnetic survey sponsored by the Nigeria Geological Survey Agency. It covers Ilesha West and Ilesha East located within Osun State of the southwestern Nigeria. The data were acquired along a series of NW-SE flight lines with a spacing of $500 \mathrm{~m}$ and average flight lines, while tie lines occur at about $2 \mathrm{~km}$ in a direction of NE-SE. The geomagnetic gradient was removed from the data using the International Geomagnetic Reference Field. The data was made available in $\mathrm{X}, \mathrm{Y}, \mathrm{Z}$ format, where $\mathrm{X}$ values represent the distance of a point from the origin pointing to the east direction; Y values represent the distance of a point from the origin in the ordinate direction while the $\mathrm{Z}$ values represent the values of the total magnetic intensity at a point. The total area covered was about $3025 \mathrm{~km}^{2}$.

The first step was to transform the digitized aeromagnetic data of Ilesha area using SURFER 8.0 version and later converting it to a gridded format.

The gridded data was now used to obtain contour map, surface map and wireframe map of the study area for qualitative analysis.

The last step was to process the gridded aeromagnetic data using potential field (PF) software on the Local Wavenumber and Analytic Signal Techniques. The result was presented using PLOTDEP program in the PF software (figure 5 and 6).

\section{THEORY:}

Analytic Signal Method (ASM): The amplitude of the Analytic Signal (AS) of magnetic anomaly can be defined according to Essam et al. (200)3 as the square root of the sum of the vertical and two orthogonal horizontal derivatives of magnetic field such that

$=\sqrt{\left(\frac{\partial M}{\partial x}\right)^{2}+\left(\frac{\partial M}{\partial y}\right)^{2}+\left(\frac{\partial M}{\partial z}\right)^{2}}$

The horizontal and vertical derivations of the magnetic field are Hilbert transform pairs of each other (Nabighian 1974). The analytic signal method has been successfully applied in the form of profile data to locate dike bodies (Atchuta Rao et al, 1981, Nabighian, 1972, Nabighian, 1974). The approach was further developed by Roset et al in 1992 for the interpretation of aeromagnetic maps. Improvements of the approach in the interpretation of aeromagnetic data were also presented by $\mathrm{Hsu}$ et al, 1998). Furthermore, Thurston and Smith (1997) presented a variation of the approach also known as local wave number.

The AS of magnetic anomalies can be easily computed. The horizontal derivations can be calculated directly from a total field grid using a simple $3 \times 3$ difference filter; both the horizontal and vertical gradient can be calculated in the frequency domain using the conventional Fast Fourier Transform (FFT) technique. MacLeod et al (1993) calculated the vertical derivations from the vertical 
integral of the magnetic field in order to produce a result that was similar to the analytic signal of Pseudo gravity. Essam et al (2003) developed a new method from which the depth for a contact model can be calculated from AS in a least-squares sense. The advantage of this method on magnetic data enhancement is that its amplitude function is always positive and does not need any assumption of the direction of the body magnetization (Jeng et al, 2003).

Local Wavenumber (LWN) or Source Parameter Imaging (SPI): Source parameter imaging (Thurston and Smith, 1997, Fairhead et al, 2004) is a profile or grid-based method for estimating magnetic source depths. The method utilizes the relationship between the source depth and the local wave number $(\mathrm{k})$ of the observed field which can be calculated for any point within a grid of data via horizontal and vertical gradients. At peaks in the local wave number grid, the source depth is equal to $\mathrm{n} / \mathrm{k}$, where $\mathrm{n}$ depends on the assumed source geometry (analogous to the structural index in Euler deconvolution) for example $\mathrm{n}=1$ for a contact, $\mathrm{n}=2$ for a dyke. Peaks in the wave number grid are identified using a peak tracking algorithm (Blakeley and Simpson, 1986) and valid depth estimates isolated. Advantages of SPI method over Euler deconvolution or spectral depth are that no moving data window is involved and the computation time is relatively short. On the other hand, there is no way to assess the reliability of each depth estimates, and the need to calculate second order derivate of the observed data means noise can be a problem. Errors due to noise can be reduced by careful filtering of the data before depths are calculated. Philips et al (2006) proposed a method of analysing the local wave number to derive estimates of source depth and structural index. This method looks at the peaks in terms of both the amplitude and curvature, and a depth estimate is generated that is independent of structural index. The structural index can be estimated from the data, and the estimate of structural index can provide a means of discriminating between reliable and spurious depth estimates.

In this method, the function used is the local wavenumber (k) (Thurston and Smith, 1997) given by:

$K(x, y)=\sqrt{\left(\frac{\partial \theta}{\partial x}\right)^{2}+\left(\frac{\partial \theta}{\partial y}\right)^{2}}$

and $\theta=\frac{\frac{\partial T}{\partial z}}{\sqrt{\left(\frac{\partial T}{\partial x}\right)^{2}+\left(\frac{\partial T}{\partial y}\right)^{2}}}$
Where $\theta$ is the local phase of the total field (Turston and Smith, 1997

The local wavenumber $\mathrm{k}(\mathrm{x}, \mathrm{y})$ is peaked over isolated contacts. Depths can be estimated without assumptions about the thickness of the source bodies (Smith et al, 1998); therefore the depth estimates may be more accurate than the minimum (or maximum) depths calculated by the other methods. In addition to the depth, the method yields a parameter called the structural index, which defines the geometry of the source. The edge of a thick body has a structural index of zero. As the thickness of the body decreases, the structural index of the edge moves toward unity.

\section{RESULTS AND DISCUSSION}

The aeromagnetic contour map (figure 3) partitioned into three (3) regions for easy qualitative analysis shows the values ranging from $-140 \mathrm{nT}$ to $100 \mathrm{nT}$. Region 3 has low relief magnetic values followed by region 1 . Region $1(0-18 \mathrm{~km}$ along the longitude) is dominated by a positive low magnetic anomaly. Region 2 (ground distance $18 \mathrm{~km}-37 \mathrm{~km}$ of longitude) is juxtaposed by the high variation in anomaly signature of the contour lines. This region is characterized by shallower magnetic source because of the concentration of different magnetic intensity values while region 3 (ground distance $38 \mathrm{~km}-55 \mathrm{~km}$ of longitude) is not only characterized by low positive and negative magnetic anomaly but also by deeper sources due to low concentration of magnetic intensity values.

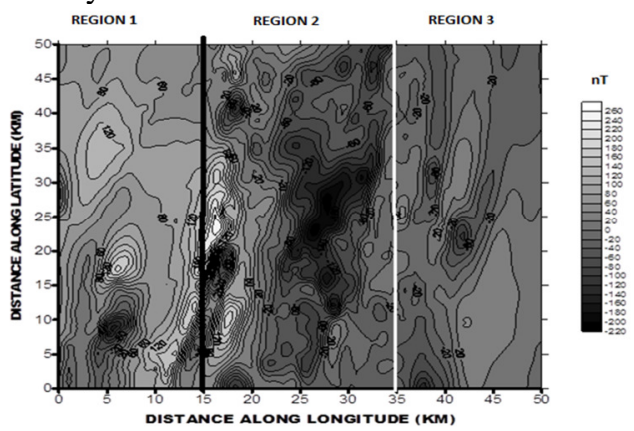

Fig 3: Magnetic Contour map of the Study Area.

The magnetic value shows a significant contrast which defines the level of magnetization of the study area. The surface map in figure 4 showed an increase in magnetic value between $0 \mathrm{nT}$ and $240 \mathrm{nT}$ with the decrease being from $-20 n T$ to $-200 n T$. The sharp edges are widely spread at the centre of the surface map (18km to $37 \mathrm{~km}$ along the longitude) arising from a strong magnetization of small bodies near the surface. The coloured surface map legend lends credence to increase and decrease in magnetic field values as the region of blue colour represent highest

Vitalis, C. Ozebo; Charles, O. Ogunkoya; Gideon, O. Layade; Victor, Makinde; Adeyinka, L. Bisilimi 
magnetic field (240nT) while region with green colour indicates the lowest magnetic field (-220nT). Figure 4 represents the wireframe of the study area after gridding which shows the apparent amplitude of magnetic source in the area.

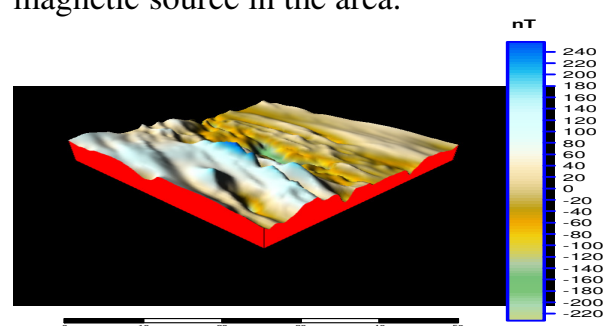

Fig 4: Surface map of the Study Area.

A complete quantitative interpretation of potential field data is to estimate three types of information about sources of geological interest: the depth, dimension and contrast in physical property. It is impossible to obtain all three types of information simultaneously without any prior information. Many different techniques have been developed, over half a century, to estimate the magnetic depth. These techniques are independent of the susceptibility contrast and work for different simplified source geometries. The techniques used in the research are Local Wavenumber (LWN) and Analytic Signal Method (ASM).

Analytic Signal Method (ASM) was performed by AS, ASDEP and PLOTDEP program from PF software. The result presented in figure 5 shows the depth to magnetic sources estimated between $0.348 \mathrm{~km}$ and $2.55 \mathrm{~km}$. The centre of each circle in figure 5 coincides with the location of the maximum for the magnetized body while the diameter of the circle is proportional to the depth estimated for the source at that point. The Analytic Signal method does not make the same assumptions with Horizontal Gradient Method and does not result in displaced contacts. However, the Analytic Signal contacts are less continuous and their directions can be influenced by flight line and other noise in the data.

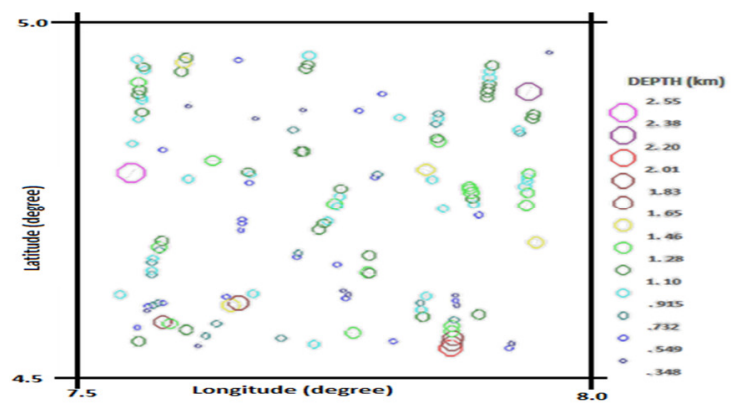

Fig 5: Depth and contact location from Analytic Signal Method (ASM).

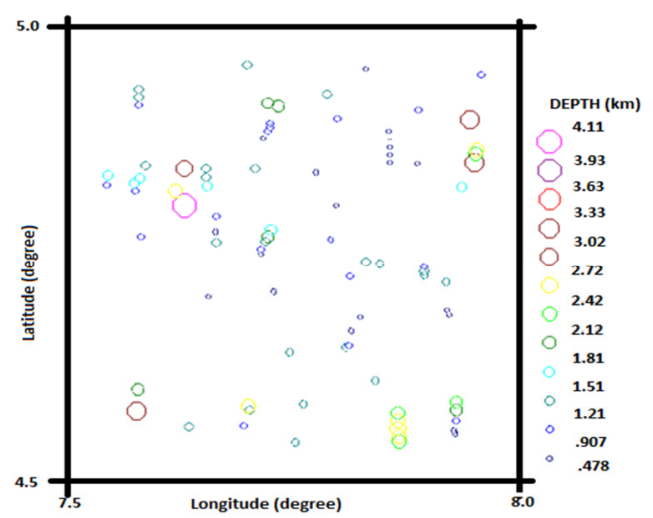

Fig 6: Depth and contact locations from Local Wavenumber (LWN)

The Local Wave Number (LWN) of the total intensity field was calculated using program LOCAL, LOCDEP and PLOTDEP. The depth estimated is between $0.478 \mathrm{~km}$ and $4.11 \mathrm{~km}$. This is presented in figure 6 . The discontinuous contacts and poor control of strike direction are common in LWN method which is also sensitive to noise in the data (figure 6).

Analytic Signal Method (ASM) shows more contact locations in figure 5. The basement depth range is $0.348 \mathrm{~km}-2.55 \mathrm{~km}$ as shown in Table 1 and it represents the lowest depth basement among the applied techniques both in minimum and maximum depth respectively. Figure 6 represents the depth and contact locations from Local Wavenumber (LWN) showing its least contact locations compared with the other technique used. The depth to magnetic sources is more predominant between $0.478 \mathrm{~km}$ and $1.51 \mathrm{~km}$ (Table 1).

Table 1: Depth Range for Predominant Locations.

\begin{tabular}{lllll}
\hline Techniques & $\begin{array}{l}\text { More } \\
\text { predominant } \\
\text { location. }\end{array}$ & $\begin{array}{l}\text { Average } \\
(\mathrm{km})\end{array}$ & $\begin{array}{l}\text { Less } \\
\text { predominant } \\
\text { location. }\end{array}$ & $\begin{array}{l}\text { Average } \\
(\mathrm{km})\end{array}$ \\
& $\begin{array}{l}\text { Shallow } \\
\text { sources } \\
(\mathrm{km})\end{array}$ & $\begin{array}{l}\text { Deeper } \\
\text { sources(km) }\end{array}$ & \\
& $0.348-1.28$ & 0.814 & $1.46-2.55$ & 2.01 \\
Asm & $0.478-1.51$ & 0.994 & $1.81-4.11$ & 2.96 \\
\hline
\end{tabular}

Conclusion: The depth to magnetic basement and its contact locations at Ilesha, Oyo state was determined in this study. The deeper magnetic sources probably depict depth to Precambrian basements, while a shallow magnetic source depicts depth to basic intrusive and/or magnetized bodies within the sedimentary cover. The contact locations are more present and continuous in Analytic Signal Method result than in that of Local Wavenumber with less and discontinuous contact locations. 


\section{REFERENCES}

Andrew R., Gordon F., Bounlem B. H. (1994). Analytic signal generation-tips and traps, IEEE transaction on signal processing, 42: 110-116.

Ansari, A.H., Alandar, K. (2009). Reduction to the pole of magnetic anomalies using analytic signal, World Applied Sciences Journal 7(4): 405 - 409.

Ajayi, T.R. (1981). On the geochemistry and origin of the amphibolites of Ife Ilesha area S.W Nigeria, Nigeria $J$. Min Geo.17:179-176.

Atchuta, R.D,. Ram-Babu, H.V., Sanker-Nurayan,, P.V. (1981). Interpretation of magnetic anomalies due the dike: the complex gradient method, Geophysics, 46:15732 - 1578 .

Blakeley, R.J., Simpson R.W. (1986). Approximating edges of source bodies from magnetic or gravity anomalies, Geophysics, 51(7):1494-1498.

Elueze, A.A. (1986). Geology of the precambranian Nigeria. Geological Surv. Nig. 22(4): 77-82.

Essam, A., Ahmed, S., Keisuke Ushijima. (2003). Interpretation of aeromagnetic data of Gebel El-Zeit area, Gulf of Suez, Egypt using magnetic gradient techniques. Memoirs of Faculty of Engineering, Kyushu University. 63 (3): 139-149.

Fairhead, J.D., Williams, S.E., Flanagan, G. (2004). Testing Magnetic Local Wavenumber Depth Estimation Methods using a Complex 3D Test Model, SEG Annual Meeting, Denver, Extended Abstract.

Folami, S.L. (1992). Interpretation of aeromagnetic anomalies in Iwaraja area, south western Nigeria, $J$. Min. Geol. 28 (2): 391-396

Hsu, S.K., Corpens, D., Shyu, C.T. (1998). Depth to magnetic source using the generalized analytic signal, Geophysics. 63: 1947-1957.

Igboama, W.N., Ugwu, N.U. (2004). Basement depth in Anambra basin determined by a dimensional data, Journal of Applied science 7 (3): 4411-4418.

Jeffrey, D.P. (1997). VAX command procedure, Unix Cshell and DOS batch file implementation: U.S. Geological Survey. Open - File Report. P 92-95.

Jeng, Y.L., Lee, C.Y., Chen Lin. M.J. (2003). Integrated signal enhancement in magnetic investigation in archaeology, Journal of Applied Geophysics. 53, 3148.

Kayode, J.S. (2009). Vertical component of the ground magnetic study of Ijebu-Ijesa, southwestern Nigeria. A paper presented of the international association of seismologist and physics of the earth interior (IASPEI) 2009 conference at Cape Town, South Africa .Jan $10^{\text {th }}-16^{\text {th }}$.

Kayode, J.S., Nyabaze, P., Adelusi, A.O. (2010). Ground magnetic study of Ilesha east, southwestern Nigeria,. African Journal of environmental science and technology. 4(3): 122-131.

Kehinde-Phillips, O.O., Gerd, F.T. (1995). The mineralogy and geochemistry of the weathering profiles over amphibolites, anthophillite and talcshicsts in ilesha schist belt, southwestern Nigeria, J. Min. Geol. 31(1): 53-62.

Macleod, I.N., Jones K., Dai, T.F. (1993). 3-D analytic signal in the interpretation of total magnetic field data at low magnetic latitude, Proceedings of the Third International Congress of Brazilian Society of Geophysics.

Nabighian, M.N. (1972). The analytical signal of twodimensional magnetic bodies with polygonal crosssection, its properties and use for automated interpretation, Geophysics, 37, 507 - 517.

Nabighian, M.N. (1974). Additional Comment of the analytical signal of two-dimensional magnetic bodies with polygonal cross-section, Geophysics, 39, 85 - 92.

Ozebo, V.C., Ogunkoya, C.O., Makinde, V., Omeike, M.O. (2015) An Estimation of Magnetic Contact Location and Depth of Magnetic sources in Ilesha, Nigeria, Using Magnetic Gradient Techniques. African Review of Physics 10: 17 - 26

Ozebo V.C., Nwodo, M.U. (2017) Interpretation of High resolution magnetic Data over Nsukka and Udi Areas of Enugu State, Nigeria. FUW Trends in Science and Technology Journal 2(1A) $182-187$.

Rahaman, M.A. (1976): A Review of the Basement Geology of South western Nigeria; Elizabeth Publishing Co. pp 41-58.

Phillips, J.D., Hansen, R.O., Blakely, R.J. (2006). The Use of Curvature in Potential-Field.

Interpretation, ASEG2006, expanded abstracts

Smith, R.S., Thurston, J.B., Dai, Ting-Fan and MacLeod, I.N. (1998). iSPI ${ }^{\mathrm{tm}}$ - the improved source parameter imaging method, Geophysical Prospecting, 46: 141-151.

Thurston, J.B. and Smith R.S. (1997). Automatic conversion of magnetic data to depth, dip and susceptibility contrast using SPI method, Geophysics. 62 (3): $807-813$.

Vitalis, C. Ozebo; Charles, O. Ogunkoya; Gideon, O. Layade; Victor, Makinde; Adeyinka, L. Bisilimi 